\title{
Practice and Reflection on the Teaching of Digital Media Art
}

\author{
Juan Huangfu \\ SIAS International University \\ Zhengzhou, China, 4751150
}

\begin{abstract}
With the large-scale development of contemporary digital technology, digital media art has had a profound effect on people's lives and generated a huge digital industry. The national universities and colleges have established an additional digital media art specialty to satisfy the requirements of social development. In contrast, the teaching skills of digital media art have lagged behind. Many schools are blindly copying other schools' training plans irrespective of the fact that digital media art is an interdisciplinary and compound discipline. They are also applying backward teaching methods that are short of practical guidance, rendering them incapable of training highlevel talents really needed by the market. This paper discusses the problems in the current teaching mainly from the aspects of the specialty construction of digital media art, basic education reformation, curriculum group design, practicality of teaching, balance between technology and art, teaching staff construction and so on based on the status quo of industrial development and talent training in China's higher education. It also attempts to, through exploration, help universities and colleges to cultivate inter-disciplinary talents truly meeting social demand in order to promote the development of digital media art in China.
\end{abstract}

Keywords—digital media art; specialty construction; teaching practice

\section{INTRODUCTION}

The 21 st century can be described as the digital age as our lives constantly change due to the rapid development and popularity of digital technology. The electronic information technology-based digital media art begins to develop and artists start to use new means for new forms of artistic creation.

Digital media art, in a general sense, refers to a multidisciplinary field where science and art are integrated to a high degree and artworks with unique aesthetic value are produced by digital and informational technology. It has exercised its irresistible influence and penetrated into many aspects of society, culture and entertainment, including games, DV, film and animation, digital design, digital illustration and other industries. The huge and fast-growing digital creative industry requires a large number of digital engineers and digital artists, which in turn promotes the rapid development of the present digital art education. In recent years, our digital media art discipline has become an integral part of art discipline system and many universities and colleges have established an additional digital media specialty or other specialties to which it is related. Since it has happened mostly in the last five years and represents an uneven and rapid level of growth, we need to reflect and research the many problems arising in regards to the discipline's construction, teaching practices, and other aspects.

\section{Digital CREATIVE INDUSTRY AND THE CURRENT SiTUATION OF EDUCATION}

The influence of digital technology on social production and market economy remains unmatched by any other production patterns in human society. The huge digital creative industry has brought a huge profit for countries leading the industry. In the United States, the country taking the leading position in the world, film and television production, game production, and individual artistic creation (along with other industries) have earned an annual economic profit of nearly tens of billions of dollar; in South Korea, the digital technology industry has generated more revenue and become more of an economic asset far than the automotive industry. At present, China's digital art industry is also developing rapidly, but the cultivation of urgently needed digital art talents fails to keep pace with this development.

The market demand helps popularize the digital education. Appropriately, a hundred universities have established the digital media specialty and more universities are making preparations. As an old poem says, "The wind blows strongly in the evening", but the popular specialty remains unpopular for employment and the social market has a shortage of talent, all of which leave China in an awkward situation. For example, the animation specialty, the most representative digital art, is a popular specialty now, and national policy encourages its further popularity. Although animation bases can be found in all places, it is actually a false prosperity. As can be gleaned from the "Graduate Employment Report" in 2013, the animation specialty has been red-carded by the state for three consecutive years. Faced with this situation, we must reflect on the disciplinary construction and the teaching methods of the digital specialty. Many universities and colleges often do not consider their own conditions and developmental directions when deciding to establish a digital art specialty but blindly copy other schools' training plans irrespective of the fact that digital 
media art is an interdisciplinary and compound discipline. Furthermore, by applying backward teaching methods and lacking practical guidance, they fail to train high-level talents actually needed by the market. In this situation, continuous reformation and improvement are required for the training and education mechanisms, especially the system and teaching method of digital media art.

\section{TO Highlight THEIR OWN CHARACTERISTICS, AND NOT TO BLINDLY FOLLOW THE TREND}

Digital media art is a cross-disciplinary course which covers a wide range of topics. In contrast, many universities and colleges fail to determine a specific and targeted specialty orientation but set a broad and plain curriculum. Until now, as far as the specialty construction of digital art is concerned, no regulations are available for the specialty setting throughout the country. In addition, the specialty is offered for a short period, so different universities and colleges have different specialty orientations and training methods. The digital field is a quickly updating field where practice always precedes employment and this situation is common at home and abroad. For this reason, all universities and colleges shall remain highly sensitive to the forefront of digital media information and conduct detailed research when formulating a specialty program and its related talent training.

A minority of domestic universities and colleges has entered their mature stage and represents their own features. Examples include: China Central Academy of Fine Arts established the digital media art specialty and oriented it towards design and art creation; Beijing Film Academy is focused more on the business direction of the digital animation specialty and directly combines the specialty teaching with the industry; China Academy of Art is primarily aimed at digital artistic creation. All schools highlight their respective characteristics and advantages, but these characteristics and advantages are not easily imitated and established by every school because these specialties need the strong support of related disciplines. Examples include: China Academy of Art established the New Media Art Department in the Fashion Academy hoping to cultivate avant-garde contemporary digital artists earliest and set up the Media and Animation School in 2004. The film discipline in Beijing Film Academy provides huge and strong support for the specialty teaching. The digital specialties in the above two universities are established by virtue of their respective disciplinary advantage; however, these resources may be unavailable to ordinary comprehensive universities and colleges.

Many domestic universities and colleges, especially ordinary comprehensive universities, are broad and vague in specialty orientation and fail to give proper guidance to the students who know nothing about the status of industrial development, set no definite goal for their own development, and are blind to learning after entering a university or college. This makes it difficult for students to be involved in the industrial practice of digital art after graduation. As for the establishment of a new digital media specialty, the training objectives and standards shall be subject to the national and provincial specialty construction. The specialty characteristics and highlights of talent training shall be emphasized based on the academies' own talent training characteristics, school history, location-based advantages, and resources condition. We should set up a specific specialty orientation and should not blindly follow the trend. Only in this way can teaching resources better support one another to achieve better results.

\section{TO UPDATE THE EDUCATIONAL PHILOSOPHY FOR STUDENTS' SUSTAINABLE DEVELOPMENT}

The development of new disciplines inevitably raises new requirements for teaching and the traditional idea of course teaching will need constant reformation in order to adapt to the rapid development and meet the requirements of the digital information age.

\section{A. To Adapt Basic Teaching to Specialty Characteristics}

In addition to the setting of basic courses (which tend to be similar to those of other design specialties), digital art design at this stage is unable to adapt itself to its own characteristics and exist independently from its follow-up specialty curriculums. This makes it difficult to integrate into the broader school curriculum. When emphasizing the universality of basic courses, we should also pay attention to a targeted combination with specialties and focus on the teaching based around different directions to ensure the teaching ideas and methods of basic courses are subject to appropriate adjustment and improvement according to new disciplinary characteristics, such as digitization, interaction, movement, etc.. For example, the animation-oriented sketching class should require more dynamic scenery and character sketches. The intensification of the training of character and scenery sketching can help lay a better foundation for future original painting animation, FLASH animation, and other courses. It is also advisable to combine the basic teaching of traditional image patterns with digital technology in order to introduce digital technology into sketching, color design, graphic design, three-dimensional modeling and other course and to get rid of the limitations on the conventional materials, production technology, concepts and other aspects. The teaching content and method of the same course should be treated differently if it is provided for a different purpose, which is particularly true in the training during basic courses.

\section{B. Cross-disciplinary Courses and Reasonable Design}

It is suggested that a reasonable curriculum system should be built based on the respective specialty orientations and disciplinary foundations of the school. Firstly, a reasonable link shall be established for courses at different levels to create a progressive structure for basic courses, technical courses and specialty-oriented courses in order to avoid disciplinary disconnection. Secondly, as for similar courses of different specialties, the design orientation shall be specific. For example, for the designing of interactive courses, New Media Art Department of China Academy of Art mainly opens the interactive installation course and other courses applied for the interaction between pure artworks 
and audience, while the Academy of Arts \& Design, Tsinghua University focuses on the web-based interaction, which is mostly applied in the information service design, both of which have a different emphasis.

It should be noted that horizontal, vertical and cross academic integration is required among courses. Digital art involves a knowledge system rooted in the fields of fine arts, art design, music, and computer application technology, to name a few. The field evolves into a new artistic form in which human rational thinking and artistic inspiration are integrated into a whole. The curriculum setting should focus on the strengthening of interdisciplinary learning and exchange, make full use of favorable peripheral resources and seek the support from arts, science, engineering and other related disciplines using multiple channels. Comprehensive universities are suggested to use its multidisciplinary advantage for interdisciplinary interaction in School of Humanities, School of Computer Science, School of Music and School of Fashion. We should break down the barriers and allow different knowledge and ideas to collide. In this way, wisdom will be generated from the assembled knowledge and students will certainly benefit.

\section{Balance between Technology and Art Teaching}

Digital technology and digital art develop and update at a speed beyond imagination. In practical application, many types of software have become out of date before being grasped thoroughly. We should therefore not view teaching shortsightedly and put exclusive emphasis on the teaching of operation techniques and skills irrespective of the education and training of humanistic qualities and personal abilities. However, most domestic universities and colleges hold an idea of "quick success and instant benefits" and adopt traditional "stereotyped teaching" which focuses more on shortsighted talent output. For this reason, although students can quickly grasp technical operation, they will fail in the late development process because of the delayed effect of these weaknesses. Technology and art are two weights on the same scale where balance can be achieved only through mutual complementation. Most of the software teaching tends to focus only on operations and homework assignments which lead students to conduct a great deal of mechanical and stylized practice but neglect the cultivation of a concept of artistic design and aesthetic accomplishment. When it comes to the difference between the United States and China in terms of digital media education, Chen Xiaowen, a professor in Department of Art, Cornell University, has pointed out that foreign teachers rarely teach software, but usually teach creative and artistic concepts by using software. For example, teachers typically introduce the basic tools and application in a simple way at a beginning of the class in a digital video, and then lead students to conduct practice aimed at certain artistic rules or philosophical thoughts across a variety of ideas and issues; students are thus expected to learn software application by themselves through reading, network and practice.

Although technology is very important for digital art, it is not the foremost element of the discipline. Technology, intended to serve people's production and life develops and innovates itself constantly. The key for measuring whether digital art design works are successful is to motivate the subjective initiative of creators and to focus on improving works' artistic expression. For this reason, creation is foremost to art design and renderings through computer operation become less important when compared to the creative process. We must therefore avoid a curriculum that results in students who are enslaved by technical tools. We should emphasize differently the technical development and the artistic expression based on a university or colleges' unique characteristics.

\section{TO IMPROVE TEACHER QUALITY AND TO ENHANCE TEACHING PRACTICE}

The ultimate goal of our curriculum teaching is to serve creative design and production, but many students can hardly meet the need of practical work after graduation due to a large gap between what they have learned and the reality of social practice. On the one hand, many universities and colleges do not have sufficient sources of teachers, especially interdisciplinary high-level teachers who lay equal emphasis on theory and practice; on the other hand, students' learning is limited within universities and colleges and kept away from the real industrial practice, which ultimately leads to the teaching of a superficial curriculum teaching with poor practicality, among other problems. Problems in the improvement of teams of teachers' ability and implementation of creative practical activities for students are what we have to solve in the teaching process.

\section{A. To Improve Teachers' Practical Level}

Teacher teams are the core resource for professional development and teaching work and have a direct effect on the long-term professional development and improvement of teaching quality. Since digital art is an emerging specialty, its teacher teams mainly comprises of young teachers. However, the teachers majoring in digital art only account for a small proportion, with the others majoring in other specialties or related specialties and are introduced to support disciplinary construction at universities and colleges and are subject to the limitations of their own specialties. Furthermore, in the late stage, it mainly introduces highly educated and newly graduated talents who are severely lacking in market experience in the digital industry. Digital art has a distinct practical characteristic, but the above teachers fail to give students the forefront and most practical guidance, while technical personnel who have been engaged in this industry and obtained a wealth of practical experience are refused as a result of low academic achievement. Most of high-level professional teachers work in a few reputed universities in China, so ordinary universities and colleges are supposed to change their perspectives in the introduction of talents for teacher team construction and get rid of limitations on degree, titles. The teaching can be promoted only when we truly stand based on talent selection.

\section{B. To Implement Practical Courses}

Almost all of universities and colleges have opened social practice courses in curriculum setting, but such 
courses have failed to achieve a practical purpose and effect. We should effectively organize or recommend that students visit and learn in large-scale digital production companies, studios, art centers, and combine that knowledge with their own studio practice and research, essentially allowing students to "go out" in order to broaden their horizon.

Ordinary universities and colleges rarely have the internship opportunities to participate in project production in this industry, so, except for some of the finest colleges, it is difficult for students to be thoroughly acquainted with knowledge, let alone to conduct innovation. Establishing an appropriate studio can help implement practical courses. Studios can provide an integrated practical creative platform for students and then promote the close combination between study and practice. For example, it is advisable to establish digital imaging studios, digital animation studios, and digital video output studios as the base where teachers conduct scientific research and students participate in internships. When involved in practical design projects, students will not learn exclusively from the empty talk in the classroom like before, but will transplant design function, materials and production to the overall design idea. Only with such practice can we cultivate and train students' responsibilities and team spirit while simultaneously raising the requirements for teachers' technical abilities and practical experience. Only the close combination between theory and practice in each teaching link can help students come up with excellent creative ideas and then implement these ideas personally.

\section{CONCLUSION}

Digital Media Art is an inevitable product of the development of digital age. Faced with the current situation where the market is in urgent need of digital media art talents, universities and colleges need to achieve significant development within their own digital media specialties. To do so, they should update their educational philosophy, straighten out their teaching system, and closely combine the social practices and explore the teaching methods and means suitable for the characteristics of digital art. This will instill students with a solid learning foundation and employmentorientated development.

\section{REFERENCES}

[1] Li Sida. Introduction to Digital Imaging, Tsinghua University Press, 2010

[2] Huang Mingfen. New Media and Western Digital Art Theory. Academia Press, 2009

[3] Liao Xiangzhong New Media Art and Creative Education. Communication University of China Press, 2008

[4] Liu Dali. Research on the Teaching of Higher Art Education, Shandong University Press, 2008

[5] Wang Jingbo. Reflection on Digital Media Art Education in Higher Art Academy. [J]. Art Panorama, 2007

[6] Xiao Yongliang. The Role of Digital Media in the Development of Creative Industry. [J]. Modern Communication, 2005 